\title{
UNDERSTANDING MID-LIFE AND OLDER AGE MORTALITY DECLINES: EVIDENCE FROM UNION ARMY VETERANS
}

\author{
Dora L. Costa \\ Working Paper 8000 \\ http://www.nber.org/papers/w8000
}

NATIONAL BUREAU OF ECONOMIC RESEARCH

1050 Massachusetts Avenue

Cambridge, MA 02138

November 2000

I have benefited from the comments of Matthew Kahn, Chulhee Lee, Nevin Scrimshaw, and Peter Viechniki. I gratefully acknowledge the support of NIH grants AG12658 and AG10120. The views expressed in this paper are those of the author and not necessarily those of the National Bureau of Economic Research.

(C) 2000 by Dora L. Costa. All rights reserved. Short sections of text, not to exceed two paragraphs, may be quoted without explicit permission provided that full credit, including (C) notice, is given to the source. 
Understanding Mid-Life and Older Age Mortality Declines:

Evidence from Union Army Veterans

Dora L. Costa

NBER Working Paper No. 8000

November 2000

JEL No. J1, I1, N3

\begin{abstract}
During the twentieth century the 17 year survival rate of 50-64 year old men rose by 24 percentage points. I examine waiting time until death from all natural causes and from all chronic, all acute, respiratory, stomach, infectious, all heart, ischemic, and myocarditis disease among Union Army veterans first observed in 1900. The effect of such specific early life infections as stomach ailments, rheumatic fever, syphilis, measles, respiratory infections, malaria, diarrhea, and tuberculosis on older age mortality depended upon the cause of death that was being investigated but all of these infections reduced cause-specific longevity. Men who grew up in a large city faced an elevated mortality risk from all causes of death controlling for later residence. The immediate effect of reduced infectious disease rates and reduced mortality from acute disease accounts for 62 percent of the twentieth century increase in survival rates and the long-run effect of reduced early life infectious disease rates accounts for 12 percent of the increase. The findings imply that although the current effects of improved public health and medical care are larger than the cohort effects, costbenefit analyses and forecasts of future mortality still need to account for long-run effects; that mortality in populations in which infectious, respiratory, and parasitic deaths are common is best described by a competing risks model; and, that the urbanization that accompanied early industrialization was extremely costly.
\end{abstract}

\author{
Dora L. Costa \\ MIT \\ Department of Economics, E52-274C \\ 50 Memorial Drive \\ Cambridge, MA 02142 \\ and NBER \\ costa@mit.edu
}




\section{Introduction}

Life expectancy in the United States at mid and older ages has been rising during the twentieth century. At the beginning of the century men's life expectancy at age 55 was 17 years and at age 65 it was 11 years. By the century's end life expectancy at ages 55 and 65 had risen to 23 and 16 years, respectively. This increase in life expectancy was extremely slow at first, rising by only about half a year during the first three decades of the twentieth century. Between 1930 and 1960 the increase was much more rapid, with increases of more than a year at age 55 and of a year at age 65. Between 1960 and 1990 life expectancy at ages 55 and 65 respectively rose by an even greater 3 and 2 years. By 1997 life expectancies at each of these ages had risen by another year. ${ }^{1}$

Several factors may explain increases in life expectancy at older ages. Advances in medical care have reduced the deadliness of chronic conditions. Cutler et al. (1998) document the increases in life expectancy from new heart attack treatments. Velkova, Wolleswinkel-Van den Bosch, and Mackenbach (1997) show that the sudden availability of medical care has an immediate effect on older age mortality. Life style changes such as the cessation of smoking or the switch to a low fat diet may account for some of the recent mortality improvements; however, the increase in smoking from the late 1900s through the first half of the twentieth century probably contributed to increased mortality rates. Occupational exposure to harmful dust and fumes has declined. Smoke and salt are no longer heavily used as food preservatives. Infectious disease rates have fallen. Men reaching age 55 in 1960 were born when 14 percent of children died before age one whereas those reaching age 55 in 1995 were born when less than 6 percent of children died before age one (see the Berkeley Mortality Database). There is extensive evidence that mid-life, young adult, and early childhood events matter to older age health and longevity (Manton, Stallard, and Corder 1997; Costa 2000b; Elo and Preston 1992; Barker 1992, 1994).

\footnotetext{
${ }^{1}$ See the Berkeley Mortality Database and Anderson 1997.
} 
But, there is also evidence that earlier life events have relatively little impact on older age mortality (Christensen et al. 1995; Kannisto, Christensen, and Vaupel 1997; Kannisto 1994). Selection may lead to only the healthiest surviving and mortality at older ages may therefore be lower than in a population not exposed to stress at young ages. Furthermore, current life events may be more important determinants of mortality than past life events.

This paper examines a past population, veterans of the Union Army, to establish the role of infectious disease early and late in life and of occupation at young and mid-life ages on older age mortality. This population was exposed to a wide variety of infectious diseases while in the army, faced very different disease experiences at young ages that depended upon the size of city of origin, faced high occupational risks, and had medical care that was ineffective at best. I can therefore examine the effect of untreated infectious disease on later mortality. Causes of death among Union Army veterans differ from those of modern populations because of the high death rates from infectious, diarrheal, and respiratory diseases that prevailed in the past. The findings therefore have implications for modeling the determinants of mortality in past populations. They also have implications for modern populations as well, because I can examine the determinants of waiting time until death from a specific cause.

The findings will help us improve our forecasts of future mortality trends and therefore help us assess the effectiveness of policies to reduce the fiscal deficits in Social Security and Medicare. The findings will also help us formulate public policies for countries undergoing an epidemiological transition. The infectious diseases and on the job hazards that were prevalent in the United States in the nineteenth century are still common, and as deadly, in many developing countries today. If ill-health among older populations arises from their experiences in early childhood or as young adults, then these years may be the appropriate ages at which to target health interventions. Finally, the findings have implications for estimates of the standard of living during industrialization in the United States and in developing countries that are rapidly 
urbanizing. If infectious disease has a long reach, then the urbanization that accompanied industrialization may have been much more costly than suggested by comparisons of urban and rural mortality rates (Williamson 1990; Steckel and Floud).

The paper begins with an overview of the empirical strategy. To help motivate the empirical specification, this section also reviews the medical literature on the relationship between infectious disease and chronic conditions. The next three sections describe the data, the regression results, and the decomposition of the twentieth century increase in survival rates. The increase in survival rates is decomposed into the portions due to reduced infectious disease rates and to occupational shifts from manual to white collar jobs. It is also decomposed into the fractions attributable to the immediate effects of reduced infectious disease rates and of mortality from infectious disease and to the long-run effects of reduced infectious disease rates. The implications of the results are discussed more fully in the conclusion.

\section{Empirical Framework}

\subsection{Specification}

I model Union Army veterans' waiting time until death from all causes or from a specific cause by means of a proportional hazard model. The hazard, $\lambda(t)$, or the rate at which spells are completed after duration $t$ given that they last until at least $t$, is

$$
\begin{aligned}
& \lambda(t)=\exp \left(x^{\prime} \beta\right) \lambda_{0}(t) \\
& \lambda(t)=\exp \left(x_{I}^{\prime} \beta_{I}+x_{C}^{\prime} \beta_{C}+x_{O}^{\prime} \beta_{O}+x_{M}^{\prime} \beta_{M}\right) \lambda_{0}(t)
\end{aligned}
$$

where $\lambda_{0}$ is the baseline hazard and $\exp \left(x^{\prime} \beta\right)$ is the relative hazard. The vector $\mathrm{x}$ consists of four basic types of variables: 1) direct indicators of episodes of infectious disease while in the army 
$\left.\left(x_{I}\right) ; 2\right)$ indicators of size of city of residence both at enlistment in 1861-1864 and at older ages in 1900, a proxy for exposure to infectious disease $\left(x_{C}\right)$; indicators of occupation at enlistment and at older ages $\left(x_{O}\right)$; and, miscellaneous other control variables $\left(x_{M}\right)$. These control variables are indicators of both early and late life events. Artisans, laborers, and farmers were more likely to suffer from respiratory symptoms than professionals or proprietors because of their greater exposure to harmful dust, fumes, and gases (Costa 2000b). Size of city of enlistment and of residence in 1900 proxy for the severity of the disease environment. Antebellum cities of over 50,000 were particularly deadly. Although by 1900 the largest cities were less deadly than midsize cities because of their earlier initiation of such sanitary reforms as water filtration (Preston and Haines 1991: 98), exposure to air-borne disease is likely to be greater in larger cities because of crowding. By 1995-1997 age-adjusted death rates were greater on average in rural than in urban areas, but this relationship varied by race, sex, and region (United States National Center for Health Statistics 2000).

I use a competing risks framework, treating individuals who die from a cause of death other than that being examined as censored, and estimate the impact of infectious disease and occupation on waiting time until death from a specific cause. I examine all natural cause mortality, mortality from chronic disease, mortality from acute diseases, all heart disease, ischemic heart disease, myocarditis, respiratory illness, infectious illness, and stomach ailments.

I determine how much of the difference in survival probabilities between Union Army veterans and a modern population is accounted for by reductions in infectious disease rates and how much by occupational shifts. I also calculate the portion of the difference attributable to immediate reductions in infectious disease rates and their mortality sequelae and the portion attributable to early life infectious disease rates. I begin by estimating hazard models for all cause mortality, A, for mortality from chronic conditions (all deaths other than infectious, respiratory, or diarrheal diseases), $H$, and for mortality from infectious and parasitic disease, $F$. The survivor 
functions, or the probabilities of not dying from cause $J$ at least until $t$ if other causes of death are precluded, $S_{J}(t), J=A, H, F$, are

$$
S_{J}(t)=\exp \left[\ln S_{J, 0}(t) \exp \left(x_{I}^{\prime} \beta_{J, I}+x_{C}^{\prime} \beta_{J, C}+x_{O}^{\prime} \beta_{J, O}+x_{M}^{\prime} \beta_{J, M}\right)\right]
$$

where $S_{J, 0}(t)$ is the baseline survivor function. Assuming no infectious disease in the army $\left(x_{I}=0\right)$ and no elevated mortality risk in large cities $\left(x_{C}=0\right)$, the survival functions become

$$
S_{I J}(t)=\exp \left[\ln S_{J, 0}(t) \exp \left(x_{O}^{\prime} \beta_{J, O}+x_{M}^{\prime} \beta_{J, M}\right)\right]
$$

Assuming elimination of infectious disease in the army and of elevated mortality risk in large cities of enlistment but no change in mortality risk in large cities in $1900\left(x_{I}=0\right.$ and $\left.x_{c}=x_{y c}\right)$, the survival functions are

$$
S_{Y I J}(t)=\exp \left[\ln S_{J, 0}(t) \exp \left(x_{Y C}^{\prime} \beta_{J, C}+x_{O}^{\prime} \beta_{J, O}+x_{M}^{\prime} \beta_{J, M}\right)\right]
$$

Finally, if the occupational distribution had been the same as that prevailing today $\left(x_{O}=x_{T O}\right)$, the survivor functions become

$$
S_{O J}(t)=\exp \left[\ln S_{A, 0}(t) \exp \left(x_{I}^{\prime} \beta_{A, I}+x_{C}^{\prime} \beta_{A, C}+x_{O}^{\prime} \beta_{A, T O}+x_{M}^{\prime} \beta_{A, M}\right)\right] .
$$

The survivor function will underestimate the effect of reduced job hazards on older age mortality because reduced hazard within occupation is not measured.

I present two different calculations decomposing the increase in survival rates into the portion due to reduced infectious disease rates and the portion due to occupational shifts. I first use the all cause mortality equation to estimate the increase in survivor probabilities assuming 
no infectious disease ( $x_{I}=0$ and $\left.x_{C}=0\right)$ and assuming today's occupational distribution $\left(x_{O}=x_{T O}\right)$,

$$
\begin{array}{r}
S_{I A}(t)-S_{A}(t) \\
S_{O A}(t)-S_{A}(t) .
\end{array}
$$

Secondly, I estimate the estimate the increase in survivor probabilities for both the chronic and acute disease specifications assuming no infectious disease at young ages $\left(x_{I}=0\right.$ and $\left.x_{C}=x_{Y C}\right)$ and today's occupational distribution. I also estimate the effect of immediate reductions in infectious disease rates and in acute disease mortality, that is eliminating infectious, respiratory, and parasitic disease as a cause of death, as

$$
S_{H}(t)-S_{A}(t) .
$$

The additional gain from eliminating infectious disease at young ages is

$$
\left[S_{Y I H}(t)-S_{H}(t)\right] .
$$

Because many individuals in the sample undoubtedly suffered from infectious disease either before or after their army experience (though perhaps less severe forms of these infections), this quantity will underestimate the gain from eliminating early life infectious disease among Union Army veterans. Dividing this quantity by the observed difference in survivorship rates between Union Army veterans and a modern population yields a rough estimate of the gain in survivorship rates due to reductions in infectious disease rates. Unobserved disease episodes among Union Army veterans will lead me to underestimate this gain whereas unobserved disease episodes among men in modern populations and unobserved changes in the scarring effects of infectious 
disease will lead me to overestimate this gain.

Decomposing the increase in survivor rates into the portion due to eliminating early life infectious disease assumes that there is a gain at older ages to eliminating infectious disease early in life. But, the relationship between residence in a large city when young or illness while in the army and mid and older age mortality could be either positive or negative. In the following subsection, I discuss this relationship, considering the linkages between specific infectious disease $\left(x_{I}\right)$, socioeconomic status $\left(x_{O}\right)$, and the major causes of death that I examine (all heart disease, ischemic heart disease, myocarditis, respiratory illness, and such stomach ailments as gastritis/duodenitis and ulcer).

\subsection{Medical Background}

The relationship between residence in a large city when young or illness while in the army and mid and older age mortality could be negative because cohorts who survive infectious diseases may acquire partial or complete immunity from such diseases as measles, typhoid, and malaria and therefore may have lower mortality rates. If genetic susceptibility to death from infectious disease or other insults at young ages is positively correlated with genetic susceptibility to develop chronic disease at older ages, then, because fewer genetically "frail" individuals survive to old age, the mortality rate of such a cohort may be lower relative to a cohort in which more genetically frail individuals survive. The deceleration in the age pattern of mortality at older ages is compatible with just such selection (Horiuchi and Wilmoth 1998).

Stress in early life may, however, lead not to selection of the fittest but to permanent scarring. As discussed below, the medical literature provides many examples of this for heart, respiratory, and stomach disease.

Infectious diseases that can affect cardiac functioning include rheumatic heart disease, late stage syphilis, measles, and typhoid fever. Acute rheumatic fever follows group A streptococ- 
cal upper respiratory tract infection, involves the joints and the heart and subcutaneous tissue, and results in damage to the heart valves and in myocarditis. Studies of typhoid and measles patients in developing countries reveal electrocardiogram abnormalities (Khosla 1981; Olowu and Taiwo 1990). Myocarditis is one of the complications of measles.

There is also increasing evidence of a link between infectious disease and atherosclerosis. Infections are known to influence lipid metabolism and may play some role in the atherosclerotic process itself by inducing damage and inflammation in the vascular endothelium in the presence of hypercholesterolemia (see reviews by Lindholt et al. 1999; Valtonen 1991; Wong, Gallagher, and Ward 1999). Infections that have been implicated include helicobacter pylori, a bacterium that causes gastritis and stomach ulcers and is transmitted through tainted food and water; chlamdyia pneumonia, a bacterium that causes acute upper and lower respiratory infections; Coxsackie B4 virus, generally causing symptoms no more serious than a common cold or sore throat; and, some herpesviridae. The evidence linking chlamdyia pneumonia to atherosclerosis is the strongest; however, helicobacter pylori infection may be especially harmful when folate absorption is reduced, either because of decreased consumption of ascorbic acid or of folates (Markle 1997). The army diet may therefore have worsened infection.

Early life upper respiratory tract infections have been implicated in later life susceptibility both to pneumonia and to chronic obstructive lung disease (e.g. Barker 1992, 1994; Wesley 1991). In the United States of the nineteenth century malaria sufferers might be at greater risk of death from respiratory distress as well. Falciparum malaria, imported to North America with slavery, is frequently accompanied by pulmonary manifestations in non-immune individuals (e.g. Gozal 1992; Hovette et al. 1998). Others at greater risk of chronic obstructive lung disease include individuals who were exposed to dust and fumes in their jobs.

Correlates of later gastritis and ulcers include infection with helicobacter pylori; socioeconomic status - manual workers are at greater risk of gastric ulcers and non-manual workers of 
duodenal ulcers (Caygill et al. 1990); and, prisoner of war status (Venn and Guest 1991). Prisoner of war status is likely to be a correlate of gastritis and ulcers among past populations as well. Fifty-nine percent of all deaths from disease at Andersonville were from diarrhea and dystentery compared to 38 percent in the Union Army as a whole (United States Surgeon General's Office 1870: 636-641; United States Surgeon General's Office 1888: 35).

\section{Data}

The data used in this paper are drawn from a unique longitudinal dataset based upon the records of the Union Army pension program (see the Appendix for a discussion of sample representativeness). ${ }^{2}$ This pension program was the most widespread form of assistance to the elderly prior to Social Security, covering $85 \%$ of all Union Army veterans by 1900 and $90 \%$ by 1910 (Costa 1998:160). The program began in 1862 when Congress established the basic system of pension laws, known as the General Law pension system, to provide pensions to both regular and volunteer recruits who were severely disabled as a direct result of military service (see Costa (1998:197-212) for a history of the Union Army pension program). The Union Army pension program became a universal disability and old-age pension program for veterans with the passage of the Act of June 27, 1890 which specified that any disability entitled the veteran to a pension. Even though old age was not recognized by statute law as sufficient cause to quality for a pension until 1907, the Pension Bureau granted the minimum pension to those age 65 unless they were "unusually vigorous." The records contain complete medical examinations conducted by a board of three examining surgeons because those with a severe chronic condition, particularly if

\footnotetext{
${ }^{2}$ The data are Aging of Veterans of the Union Army: Military, Pension, and Medical Records, 1820-1940 (ICPSR 6837), Aging of Veterans of the Union Army: Surgeons' Certificates, 1860-1940 (ICPSR 2877), Aging of Veterans of the Union Army: United States Federal Census Records, 1850, 1860, 1900, 1910 (ICPSR 6836). See also http://www.cpe.uchicago.edu/ for further information.
} 
it could be traced to war-time experience, were eligible for larger pensions. The surgeons rated the severity of specific conditions using detailed guidelines provided by the Pension Bureau.

Copious records were generated by the Union Army pension program. Pension applications included detailed medical examinations both for men whose pension application or bid for a pension increase was rejected and for men whose applications were accepted. These records have been linked to the 1900 census and to military service records. The 1900 census provides occupational and residential information and the military service records information on stress at young adult ages such as prisoner of war status and such illnesses as measles, diarrhea, tuberculosis, typhoid, rheumatism, acute respiratory infections (e.g. pneumonia, bronchitis, influenza), malaria, and war injuries.

The sample is restricted to native-born men linked to the 1900 census, aged 50 to 64 in 1900 , and on the pension rolls by $1900 .^{3}$ A surgeon's exam detailing medical conditions is available for 93 percent of men. The sample is restricted to the 48 percent of men whose pension records provide information on cause of death. For the most part, these were men with a surviving spouse and men who lived longer. Health conditions in 1900 as noted by the examining surgeons do not predict whether information on cause of death is missing. However, if men in my sample are on the whole healthier, I am likely to underestimate the impact of infectious disease and occupation on mortality. Total sample size is 2,907 . In the analysis all deaths beyond a 25 year observation period are censored. Shorter follow-up periods yield similar results but do not provide enough observations for some causes of death such as myocarditis. Beyond this 25 year observation period variables cease to have predictive power.

Causes of death were coded as heart disease, respiratory illness (chronic respiratory

\footnotetext{
${ }^{3}$ Men not on the pension rolls are not at risk of dying. The additional restrictions were made to ensure the availability of occupational and residential information for all men circa 1900 and information on size of city of residence at young ages.
} 
and pneumonia, influenza, and bronchitis), stomach ailments (gastritis/duodenitis and ulcers), infectious (including tuberculosis but excluding pneumonia, influenza, and bronchitis), cancer, diarrheal, and genito-urinary. Heart disease was subdivided into cerebrovascular, valvular, ischemic (atherosclerosis, arteriosclerosis, coronary occlusion, and coronary thrombosis), and myocarditis. ${ }^{4}$ Acute disease includes all infectious, respiratory, and diarrheal disease. Men with vague and unclassifiable causes of death tended to be those without a surviving spouse. Conditions noted by the examining surgeons in 1900 predicted mortality by cause: valvular heart disease in 1900 predicted death from valvular heart disease but not from ischemic heart disease; stroke, angina, and varicose veins predicted cerebrovascular deaths; stroke predicted death from ischemic heart disease; irregular pulse predicted death from myocarditis; bronchitis and emphysema predicted death from respiratory causes; gastritis weakly predicted death from stomach ailments; and, prostate problems predicted death from genito-urinary causes. A tumor in 1900 was not a good predictor of death from cancer, perhaps because the examining surgeons could only diagnose the tumors that they could visually observe. On the whole, however, causes of death noted on death certificates at the beginning of the twentieth century appear to be reasonably accurate.

Table 1 presents trends in causes of death. It shows major causes of death among Union Army veterans over a 25 year period and, over a 17 year period, among Union Army veterans and white men in the first National Health and Nutrition Examination Survey, a random sample of the population. This table shows that heart disease is now largely ischemic, whereas in the past, because deaths from unidentifiable heart disease were probably attributable to valvular heart

\footnotetext{
${ }^{4}$ See Fleming (1997) and Finlayson (1985) for a history of diagnosis of ischemic heart disease. Chronic and acute respiratory illnesses are classified together because of the difficulty in distinguishing between the two in cause of death information.
} 
Table 1: Causes of Death, Union Army Veterans Alive in 1900 and White Men Alive in the First National Health and Nutrition Examination Survey in 1971-1975

\begin{tabular}{lrrr} 
& 25 Year & & \\
& Follow-up & 17 Year Follow-up \\
& UA & UA & NHANES \\
\hline Proportion surviving & & & \\
$\quad$ Entire sample & 17.68 & 41.40 & 65.11 \\
$\quad$ With cause of death & 30.71 & 58.57 & 64.59 \\
Causes of death & & & \\
All Heart & 40.31 & 37.68 & 52.55 \\
$\quad$ Cerebrovascular & 10.93 & 9.59 & 0.00 \\
$\quad$ Ischemic & 5.69 & 4.59 & 41.71 \\
$\quad$ Myocarditis & 2.62 & 1.07 & 0.00 \\
$\quad$ Valvular & 5.20 & 5.00 & 1.04 \\
$\quad$ Other and unknown & 15.87 & 17.43 & 9.80 \\
Cancer & 6.47 & 5.97 & 33.42 \\
Respiratory & 11.11 & 11.16 & 0.00 \\
Infectious & 3.03 & 5.10 & 1.53 \\
Stomach & 4.27 & 3.57 & 3.63 \\
Diarrhea & 1.72 & 1.99 & 0.00 \\
Urinary & 3.26 & 1.48 & 3.06 \\
Other and unclassifiable & 17.26 & 26.30 & 5.81 \\
\hline
\end{tabular}

UA = Union Army sample, NHANES= National Health and Nutrition Examination Survey. Both samples include the foreign-born. The UA sample is not restricted to men linked to the 1900 census. Causes of death in the UA sample are for 3,856 observations. NHANES contains 1,101 observations. The follow-up survey used was National Health and Nutrition Examination Survey: Epidemiological Follow-Up Study, 1992 (ICPSR 6861). 
disease, up to 21 percent of all deaths may have been from valvular heart. ${ }^{5}$ Table 1 also illustrates the high levels of infectious, respiratory, and diarrheal disease in the past relative to today. This suggests that it may be difficult to detect the effects of early life events on all cause mortality because such current events as recent exposure to infectious and parasitic disease may be more important.

\section{Results}

Recall that I model the relationship between such early life events as infectious disease while in the army and cause specific morbidity at mid and late ages by means of a competing risks proportional hazards model,

$$
\lambda(t)=\exp \left(x_{I}^{\prime} \beta I+x_{C}^{\prime} \beta_{C}+x_{O}^{\prime} \beta_{O}+x_{M}^{\prime} \beta_{M}\right) \lambda_{0}(t)
$$

where $\lambda_{0}$ is the baseline hazard and where the estimated coefficients have the interpretation of hazard ratios for a one unit change in $x$. Deaths from causes other than those examined are treated as censored. The vector $x_{M}$ consists of age in 1900 and dummy variables indicating whether the veteran was ever wounded in the war or was ever a prisoner of war. The vector $x_{C}$ consists of dummy variables for size of city at enlistment (over 50,000, between 25,000 and 50,000, 2,500 to 25,000 , less than 2,500); size of city of residence in 1900 (one of the top 10 largest cities in the country, one of next 11th to 36th largest cities, and a smaller city or not a city). The vector $x_{O}$ consists of dummy variables indicating occupation at enlistment (professional or proprietor, farmer, artisan, laborer, or unknown) and occupation circa 1900 (professional or proprietor, farmer, artisan, or laborer). Finally, the vector $x_{I}$ consists of dummy variables specifying whether

\footnotetext{
${ }^{5}$ Valvular heart disease in 1900 was a strong predictor of waiting time until death from unidentifiable heart disease.
} 
the veteran ever suffered in the army from diarrhea or cholera, respiratory infections (bronchitis, pneumonia, and influenza), measles, typhoid, malaria, tuberculosis, rheumatic fever or rheumatic athropathies, such stomach ailments as gastritis and ulcers, and syphilis.

Table 2 presents the results for all cause mortality and for mortality from all chronic disease and from all acute (or, more precisely, infectious, respiratory, and parasitic) disease. Tables 3 and 4 present the results for all cause mortality and for mortality from respiratory illnesses, stomach ailments, infectious disease, all heart ailments except cerebrovascular, ischemic heart disease, and myocarditis. Except for deaths from infectious disease in Table 4, I cannot reject the hypothesis that all coefficients in the regressions are jointly statistically significantly different from 0 . I also cannot reject the hypothesis that the proportional hazards assumption is met. These tables do not present results for deaths from cerebrovascular, valvular heart disease, cancer, and genito-urinary causes. None of the explanatory variables were significant predictors of death from stroke, suggesting that an unobservable such as salt intake may be the culprit. Laborers were at greater risk relative to professionals and proprietors of dying from valvular heart disease, but none of the wartime disease variables were predictors. Hepatitis infection during the war was the only significant predictor of cancer deaths, perhaps because deaths from stomach cancer were a significant proportion of all recognized cancer deaths. Only a large city of enlistment predicted deaths from genito-urinary causes. None of the variables predicted violent deaths.

Tables 2, 3, and 4 illustrate the importance of distinguishing mortality by cause of death, particularly in investigating the impact of infectious disease while in the army. Stomach ailments while in the army significantly predicted mortality from all causes, all chronic disease, stomach ailments, all heart disease other than cerebrovascular, and ischemic heart disease. Stomach ailments were also a large, though not significant, predictor of myocarditis mortality. Diarrhea was a significant predictor of mortality from stomach ailments. It was also the only illness that signficantly provided protection against mortality, in this case from respiratory illness. Malaria 
Table 2: Predictors from Proportional Hazard Competing Risk Model for All Cause Disease Mortality, All Chronic Disease Mortality, and All Infectious, Respiratory, and Parasitic Mortality

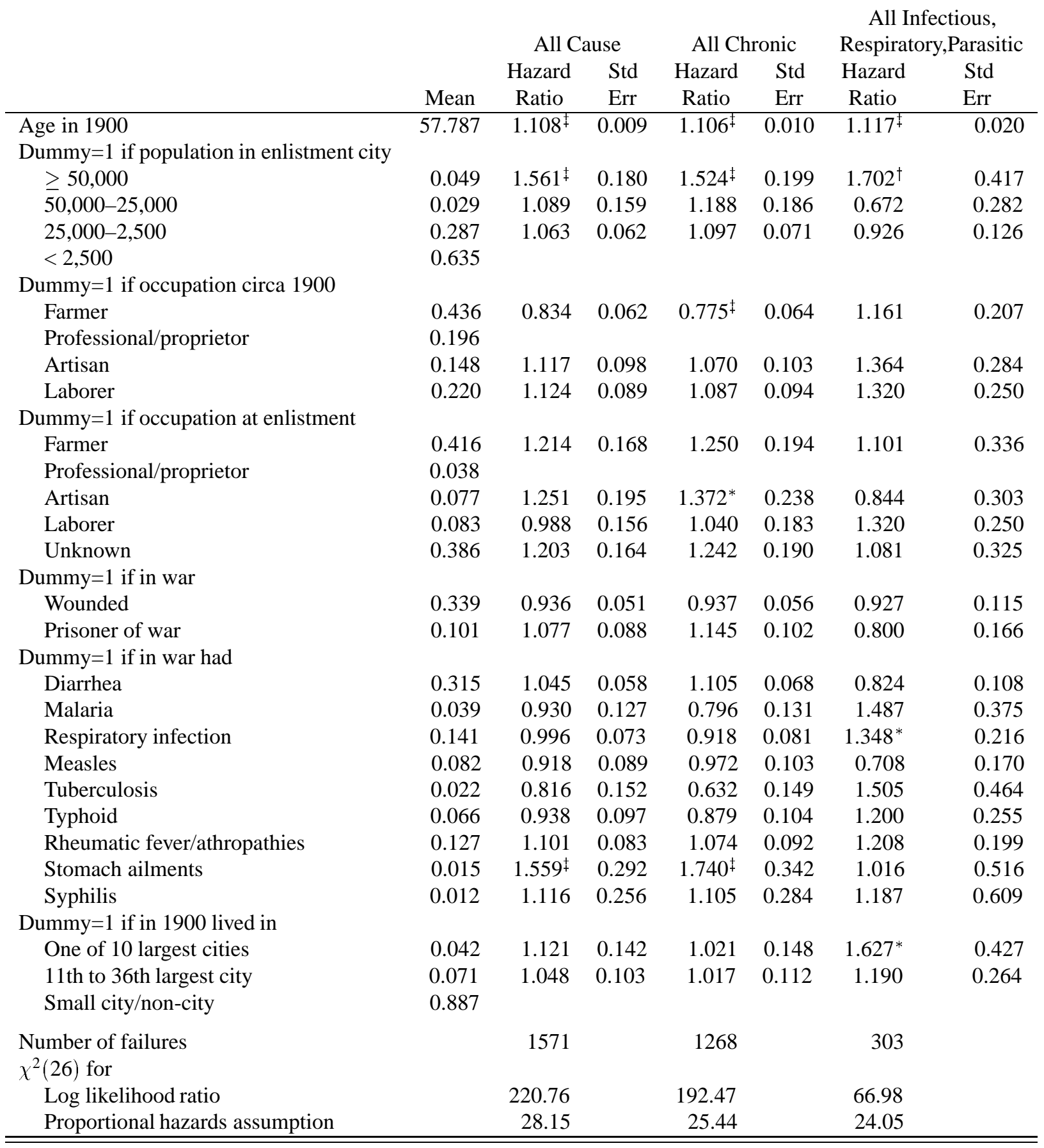

2,907 observations. The symbols $*, \hat{\dagger}$, and + indicate signifance at the 10,5 , and 1 percent level, respectively. The sample consists of Union Army veterans on the pension rolls by 1900, age 50-64 in 1900, linked to the 1900 census, and with cause of death information. The follow-up period is 25 years. Deaths during the 1918 influenza pandemic were excluded. Excluding these deaths did not materially change the results. Deaths from violence were treated as censored. The category chronic excludes all respiratory deaths, tuberculosis, diarrheal, and other parasitic and infectious diseases. These excluded deaths are in the category infectious, respiratory, and parasitic. The proportional hazards assumption is tested by testing for a non-zero slope in the generalized linear regression of the scaled Schoenfeld residuals on a function of time. 
Table 3: Predictors from Proportional Hazard Competing Risk Model of Mortality from Respiratory, Stomach, and Infectious Disease

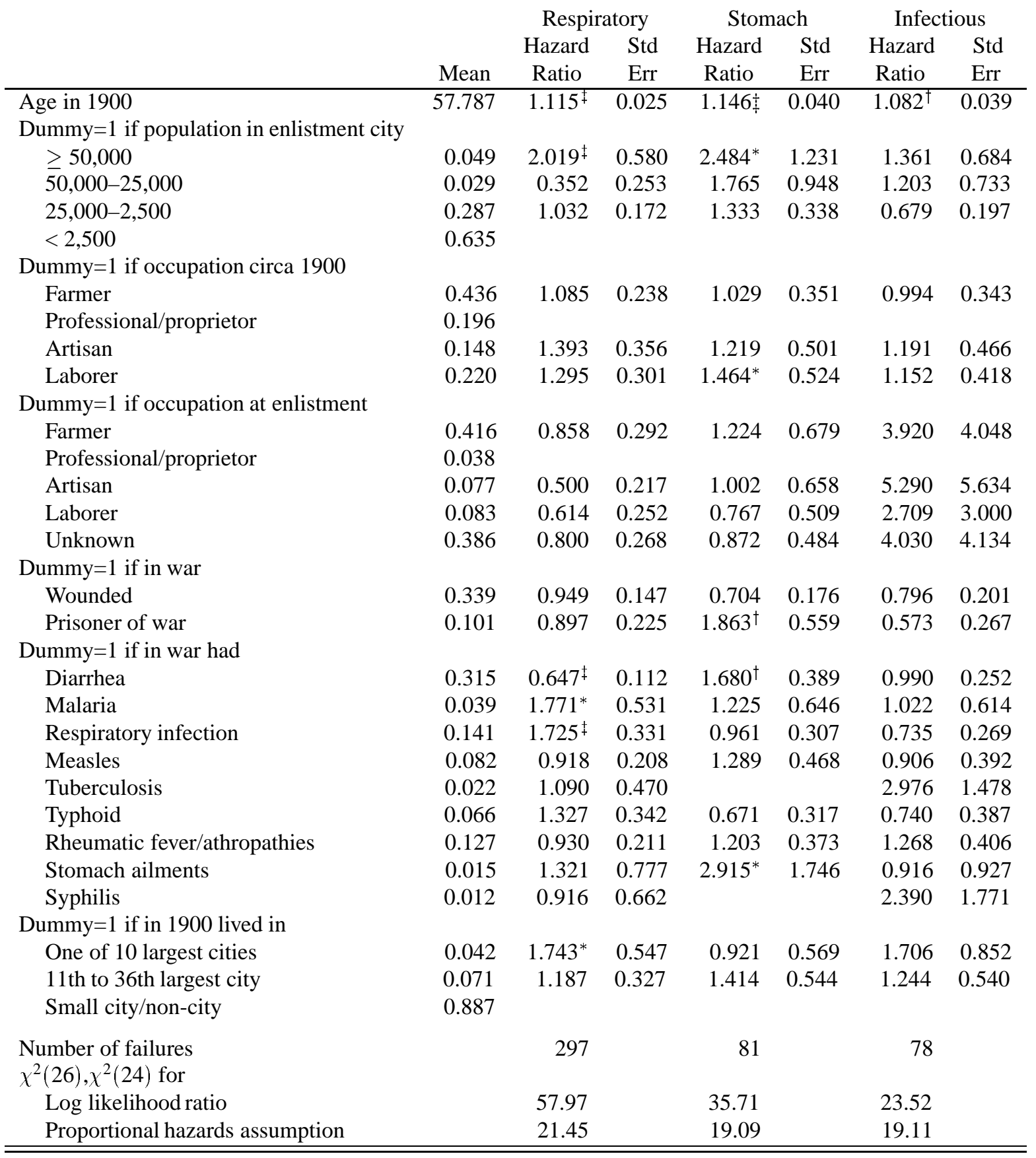

2,907 observations. The symbols $*, \hat{\dagger}$, and $\frac{\ddagger}{+}$ indicate signifance at the 10,5 , and 1 percent level, respectively. The sample consists of Union Army veterans on the pension rolls by 1900, age 50-64 in 1900, linked to the 1900 census, and with cause of death information. The follow-up period is 25 years. Deaths during the 1918 influenza pandemic were excluded. Excluding these deaths did not materially change the results. Deaths from violence were treated as censored. The category respiratory includes chronic respiratory conditions, pneumonia, influenza, and acute bronchitis. The category stomach includes gastritis/duondentis and ulcers. The category infectious includes tuberculosis. The proportional hazards assumption is tested by testing for a non-zero slope in the generalized linear regression of the scaled Schoenfeld residuals on a function of time. 
Table 4: Predictors from Proportional Hazard Competing Risk Model of All Heart Disease Except Cerebrovascular, Ischemic Heart Disease, and Myocarditis

\begin{tabular}{|c|c|c|c|c|c|c|c|}
\hline & \multirow[b]{3}{*}{ Mean } & \multicolumn{2}{|c|}{ All Heart } & \multicolumn{2}{|c|}{ Ischemic } & \multicolumn{2}{|c|}{ Myocarditis } \\
\hline & & Hazard & Std & Hazard & Std & Hazard & Std \\
\hline & & Ratio & Err & Ratio & Err & Ratio & Err \\
\hline Age in 1900 & 57.787 & $1.108^{+}$ & 0.015 & $1.168^{+}$ & 0.037 & $1.106^{*}$ & 0.056 \\
\hline \multicolumn{8}{|c|}{ Dummy $=1$ if population in enlistment city } \\
\hline$\geq 50,000$ & 0.049 & $1.558^{\dagger}$ & 0.306 & $1.941^{*}$ & 0.782 & 0.000 & 0.000 \\
\hline $50,000-25,000$ & 0.029 & 1.086 & 0.275 & $2.431^{\dagger}$ & 1.007 & 1.168 & 0.896 \\
\hline $25,000-2,500$ & 0.287 & 1.153 & 0.113 & 1.164 & 0.260 & 0.952 & 0.350 \\
\hline$<2,500$ & 0.635 & & & & & & \\
\hline \multicolumn{8}{|l|}{ Dummy $=1$ if occupation circa 1900} \\
\hline Farmer & 0.436 & 0.844 & 0.110 & $0.501^{\ddagger}$ & 0.137 & 0.514 & 0.273 \\
\hline Professional/proprietor & 0.196 & & & & & & \\
\hline Artisan & 0.148 & $1.246^{*}$ & 0.185 & 0.939 & 0.282 & 1.745 & 0.955 \\
\hline Laborer & 0.220 & $1.307^{\dagger}$ & 0.175 & 0.773 & 0.220 & $2.303^{*}$ & 1.074 \\
\hline \multicolumn{8}{|l|}{ Dummy $=1$ if occupation at enlistment } \\
\hline Farmer & 0.416 & 1.383 & 0.345 & 0.859 & 0.383 & 1.083 & 0.870 \\
\hline Professional/proprietor & 0.038 & & & & & & \\
\hline Artisan & 0.077 & 1.450 & 0.401 & 1.272 & 0.624 & 0.338 & 0.356 \\
\hline Laborer & 0.083 & 1.081 & 0.306 & 0.536 & 0.311 & 0.867 & 0.783 \\
\hline Unknown & 0.386 & 1.424 & 0.350 & 1.132 & 0.484 & 0.809 & 0.645 \\
\hline \multicolumn{8}{|l|}{ Dummy $=1$ if in war } \\
\hline Wounded & 0.339 & 0.915 & 0.085 & 0.948 & 0.195 & 0.908 & 0.306 \\
\hline Prisoner of war & 0.101 & 1.173 & 0.159 & 0.645 & 0.242 & 1.514 & 0.694 \\
\hline \multicolumn{8}{|l|}{ Dummy $=1$ if in war had } \\
\hline Diarrhea & 0.315 & 1.122 & 0.106 & 1.052 & 0.227 & 0.827 & 0.293 \\
\hline Malaria & 0.039 & 0.783 & 0.197 & 0.774 & 0.465 & 0.433 & 0.456 \\
\hline Respiratory infection & 0.141 & 0.823 & 0.114 & 0.851 & 0.267 & 1.254 & 0.522 \\
\hline Measles & 0.082 & 0.936 & 0.153 & 0.871 & 0.348 & $2.304^{\dagger}$ & 0.959 \\
\hline Tuberculosis & 0.022 & 1.159 & 0.325 & 0.797 & 0.586 & & \\
\hline Typhoid & 0.066 & 0.903 & 0.161 & 0.783 & 0.337 & 1.127 & 0.701 \\
\hline Rheumatic fever/athropathies & 0.127 & $1.218^{*}$ & 0.150 & 1.372 & 0.367 & $2.132^{\dagger}$ & 0.819 \\
\hline Stomach ailments & 0.015 & $2.109^{\ddagger}$ & 0.578 & $3.341^{\dagger}$ & 1.778 & 2.609 & 2.710 \\
\hline Syphilis & 0.012 & $1.962^{\dagger}$ & 0.593 & $2.464^{*}$ & 1.351 & $7.530^{\dagger}$ & 5.887 \\
\hline \multicolumn{8}{|l|}{ Dummy $=1$ if in 1900 lived in } \\
\hline Top 10 largest cities & 0.042 & 1.071 & 0.235 & 0.521 & 0.314 & $2.843^{\dagger}$ & 1.815 \\
\hline 11th to 36th largest city & 0.071 & 0.997 & 0.170 & 1.150 & 0.394 & 1.869 & 0.942 \\
\hline Small city/non-city & 0.887 & & & & & & \\
\hline Number of failures & & 542 & & 109 & & 42 & \\
\hline \multicolumn{8}{|l|}{$\chi^{2}(26) / \chi^{2}(25)$ for } \\
\hline Log likelihood ratio & & 104.36 & & 61.53 & & 41.12 & \\
\hline Proportional hazards assumption & & 22.45 & & 27.32 & & 28.56 & \\
\hline
\end{tabular}

2,907 observations. The symbols $*, \hat{\dagger}$, and $\stackrel{+}{+}$ indicate signifance at the 10,5 , and 1 percent level, respectively. The sample consists of Union Army veterans on the pension rolls by 1900, age 50-64 in 1900, and with cause of death information. The follow-up period is 25 years. Deaths during the 1918 influenza pandemic were excluded. Excluding these deaths did not materially change the results. The category all heart excludes cerebrovascular. The proportional hazards assumption is tested by testing for a non-zero slope in the generalized linear regression of the scaled Schoenfeld residuals on a function of time. 
and respiratory infection significantly predicted mortality from respiratory illnesses. Respiratory infection significantly predicted death from acute illnesses because this category largely consisted of respiratory illnesses. Rheumatic fever significantly predicted mortality from all heart disease other than cerebrovascular and from myocarditis and was a large though not significant predictor of death from ischemic heart disease. Syphilis was a significant predictor of death from all categories of heart disease. Measles was a significant predictor of death from myocarditis. Tuberculosis was a significant predictor of death from infectious disease. Typhoid was not a significant predictor of death from any cause.

Infectious diseases that were significant predictors of cause specific mortality also significantly predicted the probability of having a related disease state in 1900 and in 1910 . Malaria and respiratory infections while in the army significantly predicted respiratory problems at older ages. Diarrhea had a protective effect for "dullness of chest." Rheumatic fever significantly predicted tachycardia, irregular pulse, congestive heart failure, murmurs, and arteriosclerosis. Syphilis was associated with arteriosclerosis and tachycardia. Stomach ailments significantly predicted tachycardia. Not all predictors of disease states in 1900 or in 1910 were predictors of death from related causes. Whereas measles was a significant predictor of respiratory distress later in life and typhoid of irregular pulse and valvular heart disease, neither measles nor typhoid predicted death from related causes (Costa 2000a, 2000b).

Tables 2, 3 and 4 show that growing up in a large city had a lasting effect on mortality even controlling for later residence. Men who enlisted in a city of 50,000 or more faced a significantly greater risk of death from all cause mortality, from all chronic disease, from all respiratory, infectious, and parasitic disease, from respiratory illness, from stomach ailments, from all heart disease except for cerebrovascular, and from ischemic heart disease. They also faced a greater risk of mortality from infectious disease, though not significantly so. I cannot ascertain whether they faced a greater risk of death from myocarditis because of collinearities 
between large city of enlistment and large city of residence in 1900. Large city of residence in 1900 was a significant predictor of death from myocarditis, from respiratory disease, and from all respiratory, infectious, and parasitic diseases. ${ }^{6}$

The other measure of environmental stress with significant predictive power was prisoner of war status. Former prisoners of war faced substantially greater risk of death from stomach ailments, though not from other causes. Note that studies of Australian prisoners of war during World War II (Venn and Guest 1991) find that these men were at greater risk of gastritis but not of other illnesses.

Men who worked as laborers and artisans faced an elevated risk of death relative to professionals and proprietors and to farmers. Laborers were significantly more likely than professionals and proprietors to die of stomach ailments, all heart disease, and myocarditis. Artisans were significantly more likely to die of all heart disease relative to professionals and proprietors. Farmers were significantly less likely than professionals and proprietors to die of ischemic heart disease and of all chronic disease. Both artisans and laborers were more likely to die of respiratory disease (and from all acute illnesses), though not significantly so.

On the whole occupational shifts have a smaller impact on the predicted 25 year survival probability, $S(25)$, than reductions in infectious disease rates. Table 5 illustrates the effect on the predicted survival probability of setting all diseases while in the army equal to zero, setting all large city dummies equal to zero (arguably reducing infectious disease rates), and setting the occupational distribution in 1900 to that prevailing in 1970 and the occupational distribution at enlistment to that prevailing in 1920. Except for death from respiratory and infectious disease, occupational shifts have a smaller impact on the relative survival probability even though the

\footnotetext{
${ }^{6}$ Large city of residence in 1900 does not become a significant predictor of death from other causes when size of city of enlistment is omitted nor is the interaction between large city of enlistment and large city in 1900 a significant of death from respiratory heart disease.
} 
Table 5: Effect of Infectious Disease Reductions and Occupational Shifts on the Predicted Survival Rate of 60 Year Old Men

\begin{tabular}{lccrr} 
& & & $\begin{array}{c}\text { No Wartime Infections } \\
\text { and Small } \\
\text { City }\end{array}$ & $\begin{array}{c}\text { 1970/1920 } \\
\text { Occupational } \\
\text { Distribution }\end{array}$ \\
\hline All cause & & 0.259 & 0.231 \\
Respiratory & 0.241 & 0.250 & 0.868 & 0.878 \\
Stomach & 0.861 & 0.860 & 0.961 & 0.944 \\
Infectious & 0.943 & 0.954 & 0.950 & 0.956 \\
All heart except cerebrovascular & 0.951 & 0.951 & 0.674 & 0.641 \\
Ischemic & 0.646 & 0.662 & 0.904 & 0.905 \\
Myocarditis & 0.891 & 0.900 & 0.969 & 0.951 \\
\hline
\end{tabular}

Survival probabilities are probabilities of survival until death from a specific cause. Deaths from other causes are censored. All survival probabilities are predicted setting whether a veteran was ever wounded in the war or was ever a prisoner of war equal to 0 . Age is set equal to 60. Standard errors (not shown) were large.

impact of infectious disease on the survival probability is likely to be understated because of unobserved disease episodes.

\section{Explaining Rising Survivorship}

What is the role of reduced infectious disease rates and of occupational shifts from manual to white collar work in explaining the long-run increase in survivorship at older ages? The difference in 17 year survival rates between Union Army veterans and white men in NHANES was 24 percentage points. Table 6 presents two different calculations. The first calculation use the all cause mortality regression in Table 2 and sets the wartime disease dummies to 0 and all city size variables to small, yielding an increase in the predicted survival rate $\left(S_{A}(17)\right)$ in the Union Army sample of 3 percentage points and therefore explaining 14 percent of the difference in survival rates between the Union Army sample and NHANES. A similar calculation setting the occupational distribution in 1900 to that prevailing in 1970 and the occupational distribution at enlistment to 
Table 6: Decomposition of the Difference in the 17 Year Survival Rate between NHANES and the Union Army Sample

\begin{tabular}{lrr} 
& $\begin{array}{c}\text { \% Point } \\
\text { Increase } \\
\text { in UA } \\
\text { Survival } \\
\text { Rate }\end{array}$ & $\begin{array}{c}\text { \% Dif- } \\
\text { ference } \\
\text { UA and } \\
\text { NHANES }\end{array}$ \\
\hline Difference NHANES and UA survival rates=23.7\% points & & \\
1) Change in all cause mortality, $\Delta S_{A}(17)$ & & \\
$\quad$ Total infectious=0, $S_{I A}(17)-S_{A}(17)$ & 3.3 & 13.9 \\
$\quad$ Occupational shift, $S_{O A}(17)-S_{A}(17)$ & -0.2 & - \\
2) Examining both chronic and acute disease & & \\
Change in chronic disease mortality, $\Delta S_{H}(17)$ & & \\
$\quad$ Total early life infectious=0, $S_{Y I H}(17)-S_{H}(17)$ & 2.8 & 11.8 \\
$\quad$ Occupational shift & -1.0 & - \\
Change in acute disease mortality, $\Delta S_{F}(17)$ & & \\
$\quad$ Total early life infectious $=0, S_{Y}(17)-S_{F}(17)$ & 3.3 & 13.9 \\
$\quad$ Occupational shift, $S_{O F}(17)-S_{F}(17)$ & 0.3 & 1.3 \\
Increase due to eliminating immediate acute, & & \\
$S_{H}(17)-S_{A}(17)$ & 14.6 & 61.6 \\
Increase due to early life infectious, & & \\
$\quad S_{Y I H}(17)-S_{H}(17)$ & 2.8 & 11.8 \\
Total due to infectious & 17.4 & 73.4 \\
\hline
\end{tabular}

UA=Union Army, NHANES=National Health and Examination Survey. In 1) the increase in the UA survival rate was predicted based upon the all cause mortality regression in Table 2. In 2) this increase was predicted based upon the chronic and acute disease regressions in Table 2. 
that prevailing in 1920 implies that occupational shifts explain none of the difference in survival rates between the Union Army sample and NHANES because farmers faced favorable survival rates and their numbers declined. The second calculation uses the regressions for chronic and acute disease mortality in Table 2 to obtain the probability of not dying from chronic disease, $S_{H}(17)$ and the probability of not dying from infectious, respiratory, and parasitic causes, $S_{F}(17)$. Eliminating infectious disease early in life (as proxied by wartime disease dummies and by city size at enlistment) would raise each survival rate by 3 percentage points. Occupational shifts play a negligible role. Eliminating infectious, respiratory, and parasitic diseases as a cause of death would raise survival rates by 15 percent and therefore explain 62 percent of the increase in survival rates between the Union Army sample and NHANES. ${ }^{7}$ Eliminating early life infectious disease leads to a further 3 percentage point increase in survival rates and explains 12 percent of the increase in survival rates. The total reduction due to the elimination of infectious, respiratory, and parasitic disease is 17 percentage points or 73 percent of the difference in survival rates between the Union Army sample and NHANES.

\section{Implications}

This paper has shown that early life events can lead to permanent scarring. Episodes of infectious disease while in the army and exposure to infectious disease during the growing years in large cities had an impact on the 25 year survival rate of Union Army veterans aged 50 to 64 in 1900 . If there is a role for selection, it is at much older ages. None of the covariates were significant predictors of mortality after the 25 year follow-up period.

This paper has also shown that studies of past populations that seek to understand the

\footnotetext{
${ }^{7}$ This is a slight overestimate because slightly less than 2 percent of men in NHANES died from infectious disease.
} 
determinants of mortality need to examine mortality by cause because of the high prevalence of respiratory, infectious, and diarrheal deaths in past populations. The effect of specific diseases depended upon the cause of death that was being investigated. Predictors of death from various types of heart disease among Union Army veterans included stomach ailments, rheumatic fever, syphilis, and measles while in the army. Of particular note was the relationship between stomach ailments and death from ischemic heart disease, suggesting that such infections as helicobacter pylori may have played a role. Predictors of waiting time until death from respiratory disease included prior respiratory infections and malaria, which is frequently accompanied by respiratory infections in non-immune individuals. Predictors of waiting time until death from stomach ailments were prior stomach ailments and diarrhea. Tuberculosis while in the army predicted death from infectious disease at older ages, suggesting that the nodular scars left by tuberculosis in the apices of one or both lungs could be the seeds for later active tuberculosis many years later.

The results suggest that the costs of the urbanization that accompanied industrialization prior to the widespread acceptance of the germ theory of disease and the accompanying institution of sanitary reforms were high. Men who grew up in a large city faced much higher mortality rates at older ages from all causes and from both chronic and acute disease controlling for size of city of residence at older ages. Men who lived in a large city in 1900 faced a higher mortality rate from all acute (infectious, respiratory, and parasitic) causes of death.

Reduced infectious disease rates and reduced mortality from acute disease explained up to 73 percent of the increase in 17 year survival rates between the Union Army sample and men first observed in the National Health and Nutrition Examination Survey in 1971-1975. Period effects accounted for up to 62 percent of the increase in 17 year survival rates and probably depended upon public health reforms, the increased efficacy of medical care, particularly antibiotics, and improved overall health making infectious disease less deadly. Early life events explained 12 percent of the rise in survival rates - an underestimate because of unobserved infections early 
in life. Occupational shifts from manual to white collar jobs were relatively unimportant in accounting for any of the increase in survival rates. Occupational shifts were far more important in explaining declines in disability because of their role in such debilitating chronic conditions as back problems and arthritis (Costa 2000b).

The findings imply that our analyses of the costs and benefits of public health programs, particularly in developing countries, should account not only for the period effect of reduced infectious disease rates, but also for lifetime cohort effects. They also imply that our forecasts of future trends in mortality rates need to account for reductions in infectious disease rates. In the United States those who reached age 55 in 1995 were born when almost 6 percent of children died before age 1 . Those cohorts who will reach age 55 in 2025 were born when only 2 percent of children died before age 1. Although the United States has already seen most of the benefits of reductions in infectious disease rates, many developing countries are still undergoing an epidemiological transition and these countries may have much larger elderly populations than expected.

What accounts for the 27 percent of the increase in survival rates that was unexplained by reductions in infectious disease rates and in mortality from acute disease? Probable factors include the reduced use of salt and smoke as preservatives with the rise of refrigeration, perhaps the primary explanations for declines in deaths due to stroke; improved dietary and health habits; and, the increased efficacy of medical care for chronic conditions. Perhaps not coincidentally older age mortality has declined more sharply since the 1970s when the number of therapies targetted toward the elderly began to grow rapidly. Future work will use the Union Army dataset to observe the impact of untreated disease on waiting time until death and provide insights into the role of the increased efficacy of medical care in reducing mortality rates. 


\section{Appendix}

Men who entered the Union Army were probably healthier than the population as a whole. An examination of men who were rejected for military service suggests that mean height for the population was about 0.18 inches less than the mean of the recruits. Once men entered the service, rural farmers, who were the better nourished segment of society, were more likely to die because they lacked immunities to such common camp diseases as measles and typhoid (Lee 1997). However, men who survived the war (regardless of occupation) were only 0.02 inches shorter than all recruits at enlistment, suggesting that the war itself induced minimal survivorship selection on the basis of height and hence on early net nutritional status. Increased exposure to disease probably left men in worse health than when they entered the army, but by age 50 even men who had grown up in rural areas and had not served had probably been exposed to as many infectious diseases as veterans because of increased migration. Although little is known about experience of Union Army veterans from the time they left the service until they appear on the pension rolls, several tests indicate that this sample is representative of the general population before the war in terms of wealth and circa 1900 in terms of mortality experience. ${ }^{8}$

\footnotetext{
${ }^{8}$ Among all adult males age 20 and over in the households to which recruits were linked in the 1860 census, mean wealth was similar to that found in a random sample, suggesting that military service was not very selective of men of lower socioeconomic status. In fact, $95 \%$ of the sample consisted of volunteers. Cohort life expectancies of veterans who reached age 60 between 1901 and 1910 resemble the cohort life expectancies found in genealogies and the distribution of deaths from specific causes for all veterans who died between 1905 and 1915 does not differ significantly from the distribution of expected number of deaths from those causes in the death registration states in 1910 (Costa 1998:197-212).
} 


\section{References}

[1] Anderson, Robert N. "United States Lifetables, 1997." National Vital Statistics Reports. December 13, 1999. 47(28). http://www.cdc.gov/nchs.

[2] Barker, D.J.P. 1992. Fetal and Infant Origins of Adult Disease. London: British Medical Journal Publishing Group.

[3] Barker, D.J.P. 1994. Mothers, Babies, and Disease in Later Life. London: British Medical Journal Publishing Group.

[4] Berkeley Mortality Database. http://demog.berkeley.edu

[5] Caygill, CP, MJ Hill, RL Knowles, JS Kirkham, TC Northfield. 1990. “Occupational and socioeconomic factors associated with peptic ulcers and with cancers following consequent gastric surgery." Annals of Occupational Hygiene. 34(1): 19-27.

[6] Christensen, K., J.W. Vaupel, H.V. Holm, and A.I. Yashin. 1995. "Mortality among twins age 6: Fetal origins hypothesis versus twin method.” British Medical Journal. 310(?): 432-436.

[7] Costa, Dora L. 1998. The Evolution of Retirement: An American Economic History, 18801990. Chicago: University of Chicago Press.

[8] Costa, Dora L. 2000a. "Long-term Declines in Disability Among Older Men: Medical Care, Public Health, and Occupational Change.” National Bureau of Economic Research Working Paper No. 7605.

[9] Costa, Dora L. 2000b. "Understanding the Twentieth Century Decline in Chronic Conditions Among Older Men.” Demography. 37(1): 53-72.

[10] Cutler, David, Mark McClellan, Joseph P. Newhouse, and Dahlia Remler. 1998. "Are medical prices declining? Evidence from heart attack treatments." Quarterly Journal of Economics. 113(4):

[11] Elo, Irma T. and Samuel H. Preston. 1992. "Effects of early-life conditions on adult mortality: A review." Population Index. 58(2): 186-212.

[12] Finlayson, Rodney. 1985. "Ischaemic heart disease, aortic aneurysms, and atherosclerosis in the City of London, 1868-1982." in W.F. Bynum, C. Lawrence, and V. Nutton, Eds, The Emergence of Modern Cardiology. Part of series, Medical History. Supplement No. 5: 151-168,

[13] Fleming, P.R. 1997. A short history of cardiology. Amsterdam-Atlanta, GA: Rodopi.

[14] Horiuchi, Shiro and John R. Wilmoth. 1998. "Deceleration in the age pattern of mortality at older ages.” Demography. 35(4): 391-412. 
[15] Kannisto, V. 1994. Development of oldest-old mortality, 1950-1990. Odense, Denmark: Odense University Press.

http://www.demogr.mpg.de/Papers/Books/Monographs1/OldestOld.htm

[16] Kannisto, V., K. Christensen, and J.W. Vaupel. 1997. "No increased mortality later in life for cohorts born during famine.” American Journal of Epidemiology. 145(11): 987-994.

[17] Lee, Chulhee. 1997. "Socioeconomic background, disease, and mortality among Union Army recruits: Implications for economic and demographic history." Explorations in Economic History. 34: 27-55.

[18] Manton, K.G., E. Stallard, and L. Corder. 1997. "Changes in the Age Dependence of Mortality and Disability: Cohort and Other Determinants.” Demography. 34(1): 135-7.

[19] Preston, S.H. and M. Haines. 1991. Fatal Years: Child Mortality in Late Nineteenth Century America. Princeton, NJ: Princeton University Press.

[20] Steckel, R.H. and R. Floud (Eds). 1997. Health and Welfare during Industrialization. Chicago: University of Chicago Press.

[21] United States Center for Health Statistics. 2000. Health, United States, 2000 with Adolescent Health Chartbook. Washington, DC: United States Government Printing Office. http://www.cdc.gov/nchs

[22] United States Surgeon General's Office. 1870. Medical and Surgical History of the War of the Rebellion (1861-1865). Part I. Volume I. Medical History. Washington DC: Government Printing Office.

[23] United States Surgeon General's Office. 1888. Medical and Surgical History of the War of the Rebellion (1861-1865). Part III. Volume I. Medical History. Washington DC: Government Printing Office.

[24] Velkova, A., J. Wolleswinkel-Van den Bosch, and J. Mackenbach. 1997. "The East-West Life Expectancy Gap: Differences in Mortality from Conditions Amenable to Medical Intervention.” International Journal of Epidemiology. 26(1): 75-84.

[25] Venn, AJ and CS Guest. 1991. "Chronic morbidity of former prisoners of war and other Australian veterans." Medical Journal of Australia, 155(10): 705-7,710-12.

[26] Wesley, A.G. 1991. "Prolonged After-Effects of Pneumonia in Children." South African Medical Journal. 79(2): 73-76

[27] Williamson, Jeffrey. 1990. Coping with City Growth During the British Industrial Revolution. Cambridge-New York: Cambridge University Press. 